DOI: $10.4274 /$ jarem.galenos.2021.35744

J Acad Res Med 2021;11(1):107-116

\title{
Analysis of Pregnancy and Lactation-related Expressions in the Summary of Product Characteristics and Patient Information Leaflets of the Drugs Used for the Treatment of Nausea and Vomiting
}

\author{
(1) Volkan Aydın1, (1) Ayfer Bahar2, (1) Dilara Bayram2, (1) Caner Vızdıklar2, (1) Ahmet Akıcı² \\ ${ }^{1}$ ístanbul Medipol University International School of Medicine, Department of Medical Pharmacology, İstanbul, Turkey \\ ${ }^{2}$ Marmara University Faculty of Medicine, Department of Medical Pharmacology, İstanbul, Turkey
}

Cite this article as: Aydın V, Bahar A, Bayram D, Vızdıklar C, Akıcı A. Analysis of Pregnancy and Lactation-related Expressions in the Summary of Product Characteristics and Patient Information Leaflets of the Drugs Used for the Treatment of Nausea and Vomiting. J Acad Res Med 2021;11(1):107-116

\begin{abstract}
Objective: Concerns and limited data on drug use in pregnancy and lactation raise the importance of relevant information in summary of product characteristics (SmPC) and patient information leaflets (PIL). This study aimed to examine the consistency of the information related to pregnancy/ lactation periods in SmPCs/PILs of drugs used for the treatment of nausea/vomiting.

Methods: Details of the statements regarding pregnancy and lactation periods included in the current SmPCs/PILs of a total of 118 preparations, 21 of which were original, belonging to 12 drugs with nausea/vomiting indication, were examined. SmPCs/PILs of the generic drugs was compared with that of the original drugs to identify any "minor" or "major" difference.

Results: Any of SmPCs or PILs did not contain pregnancy indication or related posology information. Pregnancy was contraindicated in all tropisetron preparations; pregnancy in $38.5 \%$ and lactation in $46.2 \%$ of metoclopramide preparations; and lactation in $66.7 \%$ of dimenhydrinate preparations. It is stated that drug is passed in milk and placenta in $60.2 \%$ and $35.6 \%$ of SmPCs respectively. The presence of the expression regarding the placental passage showed inconsistency only among metoclopramide preparations. The presence of "pregnancy" and "lactation" in the "cautions before use" section of the PILs showed intra-drug variations for dimenhydrinate, metoclopramide, ondansetron, and domperidone. Except aprepitant, at least one major difference was detected between the SmPCs/PILs of original and generic preparations. Major differences were most commonly (15.0\%) seen in the lactation section of the PILs.

Conclusion: It was determined that presence of specific expressions that may be critical for clinical practice, like the management of nausea/vomiting in pregnancy, might differ in the informative documents of medicinal products. It is noteworthy that there is at least one major difference in the documents of six of the seven drugs and that the warnings/precautions in the SmPCs/PILs of the originals of the drugs vary considerably from those of the generics. These findings indicate the need for new approaches in terms of both standardization and usefulness in clinical practice when developing informative content in SmPCs/PILs.
\end{abstract}

Keywords: Pregnancy, nausea, vomiting, generic, summary of product characteristics, patient information leaflet

ORCID IDs of the authors: V.A. 0000-0002-8511-6349; A.B. 0000-0001-9794-9033; D.B. 0000-0001-7037-353X; C.V. 0000-0002-9558-1914; A.A. 0000-0002-8593-0818.

Corresponding Author/Sorumlu Yazar: Ahmet Akıcı, E-mail: ahakici@gmail.com
Received Date/Geliş Tarihi: 02.03.2021 Accepted Date/Kabul Tarihi: 11.04.2021

@C Copyright 2021 by University of Health Sciences Turkey, Gaziosmanpaşa Training and Research Hospital. Available on-line at www.jarem.org 


\section{INTRODUCTION}

Many medical conditions that are directly related to pregnancy or not may require the mother to take a medication (1). Physiological changes experienced during pregnancy, lactation and the process of placental development affect some pharmacokinetic and pharmacodynamic properties of the drugs in these individuals (2). On the other hand, it was revealed that the use of drugs in this period should not be ignored in terms of teratogenicity, as a result of the phocomelia cases seen in the children of pregnant women who used thalidomide in the early 1960s (3). There is limited information to adequately reflect the differences in substance, especially in new drugs. Conducting phase studies in pregnant and reproductive women was banned by the American Food and Drug Administration (FDA) in 1977, and in the mid-nineties, it was decided that women in this group were included in the studies on the condition of proving that they were not pregnant and on the condition of contraception. For this reason, information on the effects of drugs during pregnancy in humans can only be collected in line with limited data obtained from pregnant women who have already used the drug (4). In a study conducted in the United States of America (USA), it was reported that the mean time until the safety status of a new drug with an "uncertain" risk of teratogenicity to be included in a specific category was 27 years (5). This situation indicates the difficulty of processing and transferring the data obtained regarding a sensitive process such as pregnancy. New information gained from the routine use of the drug in these special populations over the years after the drug is licensed is reflected in drug information resources.

Among the reference sources for pharmaceutical preparations, it is expected that the content in the summary of product characteristics (SmPC) and patient information leaflets (PIL) for healthcare professionals should consist of standard information based on the current literature and compatible between each preparation of a drug as much as possible. Health authorities make various regulations in order to protect the standards and convey the necessary information to their interlocutors, provide available sources and make the necessary corrections and carry out the related audit and follow-up procedures. In Turkey, while standard information on drugs was presented under the name of "prospectus" in the medicine box in the past, it was rearranged as to consist of two documents, SmPC and PIL as of 2005 (6). There may be difficulties in reflecting the limited information that can be obtained regarding the gestational period to SmPCs/ PILs. Various inconsistencies can be encountered in terms of compliance, following up-to-date literature, and indications in the information contained in the aforementioned documents $(7,8)$. For example, factors such as teratogenicity information, are taken more cautiously while obtaining a license, and they may change with the experience of use in pregnancy over the years, and that the generic preparations that are later on the market can find this information more when they are licensed, which may disrupt the compatibility between the information of the same active substance in the preparations (7).
Nausea and vomiting are common clinical conditions (60-70\%) during pregnancy, especially in the first trimester (9). It has been reported that $60 \%$ of pregnant women used medication for nausea and vomiting at least once during pregnancy (10). Due to teratogenicity and potential adverse effects concerns, both physicians, pharmacists and patients experience various reservations about drug use during pregnancy and lactation (11). SmPCs and PILs are among the basic sources of information that healthcare professionals and patients are recommended to apply to obtain reliable practical information about these special periods, especially indications and posology. The accuracy, coverage, standardization and usefulness of the information on pregnancy and lactation in these resources are of great importance.

In this study, it was aimed to examine the compatibility of the expressions related to pregnancy and lactation in the SmPCs and PILs of nausea and vomiting drugs for the original and generic preparations.

\section{METHODS}

Drugs with nausea or vomiting indication in the SmPCs were determined. Among them, there were twelve active substances of which at least one product registered by Turkish Medicines and Medical Devices Agency (TMMDA) (dimenhydrinate, trifluoperazine, lorazepam, ondansetron, granisetron, tropisetron, palonosetron, aprepitant, trimethobenzamide, metoclopramide, itoprid and domperidone) included in the study (Table 1). Cannabinoid and scopolamine, which are known to be used frequently in nausea and vomiting, were not included in the study because they did not have their preparations registered in TMMDA, as well as $\mathrm{H}_{2}$ receptor blockers and pyridoxine which were not directly declared as indicated for nausea or vomiting. In

\section{Table 1. List of antiemetic drugs included in the study}

\begin{tabular}{|c|c|c|c|}
\hline \multirow{2}{*}{$\begin{array}{l}\text { Drug groups } \\
\text { examined (ATC) }\end{array}$} & \multicolumn{3}{|c|}{ Drugs included } \\
\hline & Active ingredients & $\begin{array}{l}\text { ATC-5 } \\
\text { code }\end{array}$ & $\begin{array}{l}\text { Number of } \\
\text { preparations }\end{array}$ \\
\hline $\begin{array}{l}\text { Antihistamines } \\
\text { (R06) }\end{array}$ & Dimenhydrinate & R06AA02 & 3 \\
\hline $\begin{array}{l}\text { Antipsychotics } \\
\text { (N05A) }\end{array}$ & Trifluoperazine & N05AB06 & 4 \\
\hline $\begin{array}{l}\text { Benzodiazepines } \\
\text { (N05BA) }\end{array}$ & Lorazepam & N05BA06 & 2 \\
\hline \multirow{4}{*}{$\begin{array}{l}\text { Serotonin } 5-\mathrm{HT} 3 \\
\text { antagonists } \\
\text { (A04AA) }\end{array}$} & Ondansetron & A04AA01 & 37 \\
\hline & Granisetron & A04AA02 & 25 \\
\hline & Tropisetron & A04AA03 & 2 \\
\hline & Palonosetron & A04AA05 & 18 \\
\hline \multirow{2}{*}{$\begin{array}{l}\text { Other antiemetics } \\
\text { (A04AD) }\end{array}$} & Aprepitant & A04AD12 & 2 \\
\hline & Trimethobenzamide & A04AD & 4 \\
\hline \multirow{3}{*}{ Prokinetics (A03F) } & Metoclopramide & A03FA01 & 13 \\
\hline & Itopride & A03FA07 & 1 \\
\hline & Domperidone & A03FA03 & 7 \\
\hline
\end{tabular}


addition, corticosteroids with many indications and combination preparations containing more than one active ingredient were not included in the study.

The SmPCs/PILs information of a total of 118 preparations (97 generic and 21 original) consisting of different strength and forms of the twelve drugs included in the study were examined. The expressions related to pregnancy and lactation period in the current SmPCs and PILs of original and generic preparations of these drugs were evaluated in detail. It was analyzed whether there was any statement regarding pregnancy and lactation under "therapeutic indications", "posology and method of administration" and "contraindications" headings in the SmPCs and the "cautions before use" heading in the PILs of the drugs and also whether there was any statements regarding the passage of the drug to milk or placenta in the SmPCs.

Statements under the "women with childbearing potential", "pregnancy period", "lactation period", "reproductive ability", "undesirable effects" headings in SmPCs and "pregnancy" and "lactation" headings in PILs were gradually evaluated by a total of five pharmacologists, including two experts and three residents. It was determined how many original expressions were used under each heading in the SmPCs/PILs for each drug examined.

The comparison of the expressions in the generic and original preparations was made specifically for seven drugs (dimenhydrinate, ondansetron, granisetron, palonosetron, aprepitant, trimetobenzamide, domperidone), each of which has at least one original and generic preparation registered in TMMDA. The expressions in the related titles in the SmPCs/PILs of the generic preparations of these drugs were analyzed using the method we used in our previous study (7). Accordingly, the original preparations were compared with reference and the expressions were examined in three groups as those with "similar", "minor difference" or "major difference". When comparing with its generic, if different pharmaceutical forms of the original drug of an active substance were found, the information of the original preparation to which the drug was the same/closest as the pharmaceutical form was used. Phrases were considered "similar phrases" if they were exactly the same or contained several different words giving the same meaning. The existence of fundamental differences such as "discontinuation of the drug", "not recommending its use", "not advising its use", the amount of data being different, or the presence of different/missing statements regarding the drugrelated adverse effect risk are considered as "major difference" in the relevant statement. The characteristics of the major differences detected were examined for each drug. Smaller scale differences that did not fit the definition of major difference were accepted as "minor difference". In the SmPCs/PILs of the seven drugs that were compared, whether the expressions about "pregnancy" and "lactation" were included under the above-mentioned headings were also evaluated in terms of generics and originals. The investigations in the study were carried out using the most up-todate SmPCs/PILs registered in TMMDA in September 2019. This study did not require patient consent because it did not contain any patient data.

\section{Statistical Analysis}

In this descriptive study, the data were expressed as numbers and percentages for categorical variables. Statistical analysis was performed with GraphPad Prism 5.0 program.

\section{RESULTS}

\section{Indication, Contraindication and Warning Signs}

In the study, it was determined that there were a total of 97 generic preparations in different "strength and forms" of 21 original products in different "strength and forms" with licence in Turkey of 12 active substances whose SmPCs/PILs information were examined, and that there were 48 different companies with licenses for these products.

Pregnancy categories of the preparations were B (83.1\%), C $(15.2 \%)$ and D (1.7\%). It was observed that none of the examined 118 preparations had pregnancy and hyperemesis gravidarum indications in their SmPCs, and there was no statement regarding pregnancy in the "posology" section of any drug. Pregnancy in seven preparations [metoclopramide $(n=5 ; 38.5 \%)$, tropisetron $(n=2 ; 100 \%)$, lactation in eight preparations [dimenhydrinate $(n=2 ; 66.7 \%)$, metoclopramide $(n=6 ; 46.2 \%))$.$] were among the$ contraindicated situations. Under the heading of "cautions before use" in PILs, "pregnancy" was included in all preparations of itopride and tropisetron, $33.3 \%$ of dimenhydrinate, $24.3 \%$ of ondansetron and $38.5 \%$ of metoclopramide. Again, under the same heading, "lactation" was found in $24.3 \%$ of ondansetron, $69.2 \%$ of metoclopramide and $28.6 \%$ of domperidone in all preparations of dimenhydrinate and itopride (Table 2).

\section{Findings of Transition to Placenta and Milk}

Expressions related to the transition to the placenta were found in the SmPC of $35.6 \%(n=42)$ of the preparations included in the study. The presence of this statement was inconsistent only in metoclopramide preparations, and this statement was included in $76.9 \%(n=10)$ of the preparations. Other drugs for which information on placental transfer was indicated were palonosetron, tropisetron, dimenhydrinate, lorazepam, and domperidone. In the $\mathrm{SmPC}$ of $60.2 \%(n=71)$ of the preparations examined, it was found that the drug was transferred to milk. While there is information that the drug passes into breast milk in animal studies in 31 (26.3\%) preparations belonging to domperidone, dimenhydrinate, trifluoperazine, lorazepam, aprepitant and metoclopramide, it is stated that tropisetron, ondansetron and itopridine in total 40 (33.9\%) preparations are passed into milk in all preparations was taking place. In the preparations of granisetron, palonosetron and trimethobenzamide $(n=47)$, it was stated that it was not known whether the drug passed into the milk (Table 2).

\section{Findings of Compatibility Between Preparations}

It was observed that the number of unique statements under each heading examined was the highest $(n=27)$ in the section 
Table 2. The number of original and generic preparations for each active substance, pregnancy category, and the percentage of preparations in which the relevant expression is included in the parameters evaluated as "exists/does not exist"

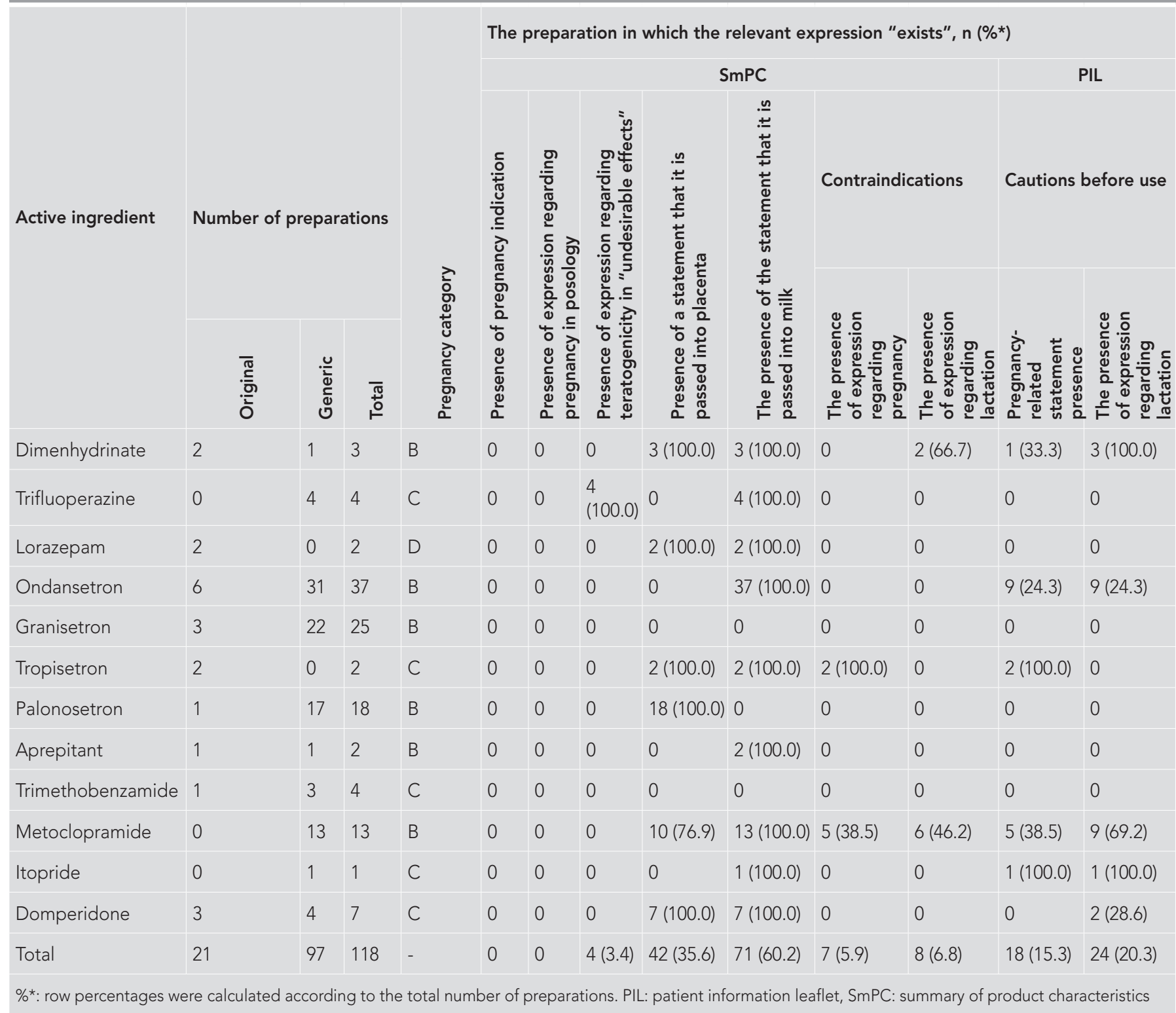

on pregnancy in the SmPCs, followed by the statement about pregnancy $(n=22)$ and lactation $(n=21)$ in the PILs. Ondansetron, which has 37 preparations, was the drug that contained the most unique expressions for each title. It was determined that only trifluoperazine preparations included a statement regarding teratogenicity ("neonatal withdrawal syndrome seen in pregnancy, post-pregnancy and perinatal conditions") under the title of "undesirable effects" and this expression was the same in all preparations of the drug. It was observed that the preparations of lorazepam and tropisetron used a single expression in each of the titles examined, and there was consistence between the preparations (Table 3).

The expressions in the SmPCs/PILs of the generic preparations of seven drugs with at least one original and generic preparation registered in the TMMDA were compared with the original preparations. It was observed that there were more major differences in the related titles in the PILs than those in the SmPC. A major difference was detected in 15\% of the preparations in the statement partabout lactation in PILs, and in 13.7\% in the expression part about pregnancy. In the SmPC, all of the differences detected in the ondansetron and trimethobenzamide preparations in the expressions for women of childbearing age and in the preparations of the drugs other than granisetron and palonosetron in the expressions about pregnancy were minor. It was determined that there was a difference in the expression related to lactation in the SmPC for other drugs except palonosetron and this difference was at a major level in granisetron, trimethobenzamide and domperidone. The differences in the expression regarding fertility were minor in ondansetron and aprepitant preparations, and major in palonosetron and trimethobenzamide preparations. It was determined that there is a difference between the preparations of 
Table 3. The distribution of the specific expression diversity used in the parameters examined for pregnancy, lactation, fertility and teratogenicity in the subtitles of the summary of product characteristics and patient information leaflets for each drug

\begin{tabular}{|c|c|c|c|c|c|c|c|c|}
\hline \multirow{3}{*}{ Active ingredients } & \multirow{3}{*}{$\begin{array}{l}\text { Number of } \\
\text { preparations }\end{array}$} & \multicolumn{7}{|c|}{ Number of original expressions used } \\
\hline & & \multicolumn{5}{|c|}{ SmPC } & \multicolumn{2}{|c|}{ PILs } \\
\hline & & $\begin{array}{l}\text { Statement } \\
\text { for women of } \\
\text { childbearing age }\end{array}$ & $\begin{array}{l}\text { Pregnancy- } \\
\text { oriented } \\
\text { statement }\end{array}$ & $\begin{array}{l}\text { Lactation } \\
\text { related } \\
\text { statement }\end{array}$ & $\begin{array}{l}\text { Fertility } \\
\text { related } \\
\text { statement }\end{array}$ & $\begin{array}{l}\text { Statement } \\
\text { about } \\
\text { teratogenicity }\end{array}$ & $\begin{array}{l}\text { Pregnancy- } \\
\text { oriented } \\
\text { statement }\end{array}$ & $\begin{array}{l}\text { Lactation } \\
\text { related } \\
\text { statement }\end{array}$ \\
\hline Dimenhydrinate & 3 & 1 & 3 & 2 & 1 & - & 2 & 2 \\
\hline Ondansetron & 37 & 3 & 4 & 3 & 2 & - & 3 & 3 \\
\hline Granisetron & 25 & 1 & 2 & 3 & 1 & - & 1 & 2 \\
\hline Tropisetron & 2 & 1 & 1 & 1 & 1 & - & 1 & 1 \\
\hline Palonosetron & 18 & 1 & 1 & 1 & 2 & - & 2 & 2 \\
\hline Itopride & 1 & 1 & 1 & 1 & 1 & - & 1 & 1 \\
\hline Domperidone & 7 & 2 & 4 & 2 & 1 & - & 2 & 3 \\
\hline $\begin{array}{l}\text { All medications } \\
\text { studied }\end{array}$ & 118 & 16 & 27 & 20 & 17 & 1 & 21 & 22 \\
\hline
\end{tabular}

all drugs except granisetron in the expression part for pregnancy in PIL and this difference is major in ondansetron preparations. All of the differences between the original and generic preparations of other drugs except granisetron and aprepitant were found to be major in the expression section regarding lactation in the PILs (Table 4).

The major differences determined were in the statements about lactation and fertility in the SmPCs, and in the statements about pregnancy and lactation in the PILs. In the SMPC, the most common reason for the major difference related to lactation was "the lack/presence of the statement that the use of the drug is not recommended" in the lactation part, while in the PILs, the "lack of the statement about not using/not leaving the drug" in the lactation part. In terms of domperidone, the lack of expression regarding the cardiac adverse effects that will arise due to the drug in the baby in the lactation section in both SmPCs and PILs was determined as the reason for the major difference (Table 5).

Whether or not a statement about pregnancy or lactation was included in certain titles examined in the SmPCs/PILs of seven drugs with at least one generic preparation was compared with the original preparation. Accordingly, although the original preparation of dimenhydrinate has a statement regarding lactation in contraindications in the SmPC, such a statement is not included in one generic preparation available in the market; in addition, while there was no statement regarding pregnancy in the "cautions before use" section in the PIL of the original preparation, it was determined that this expression was included in the generic preparation. Under the same heading, "lactation" was present in one (25.0\%) of the generic preparations of domperidone and nine (29.0\%) of ondansetron, although it was not included in their original preparations. Unlike the original preparation of ondansetron, "pregnancy" was found in nine generic preparations (29.0\%) in the "cautions before use" section. The generic preparations of trimethobenzamide, aprepitant, granisetron and palonosetron were consistent with the original preparations in these titles examined in terms of whether they included the terms "lactation" or "pregnancy".

\section{DISCUSSION}

In this study, important findings were made that there were various differences in the expressions related to pregnancy and lactation periods in SmPCs/PILs of the drugs used for nausea and vomiting. It is noteworthy that none of the preparations of the active substances included in the study are among the indications of pregnancy-related conditions in SmPCs and PILs, and the posiology is not specifically specified. The fact that this information is not clearly mentioned in these documents may be associated with the inadequacy of the literature on the use of these drugs during pregnancy and lactation. In addition, although none of the drugs examined were in the category " $X$ ", which is considered teratogen, the fact that pregnancy in about one of every 16 preparations and lactation in one of every 14 preparations as being counted among contradictions indicates that there are inconsistencies within the documents themselves. The fact that the presence of the information about the passage to placenta and 
Table 4. The number of generic preparations that differ from the expressions in the SmPCs/PILs of the original preparations of drugs, and the percentage distribution of generic preparations with a major difference in each of the expressions

SmPC

\begin{tabular}{|c|c|c|c|c|c|c|c|c|c|c|}
\hline \multirow[t]{2}{*}{$\begin{array}{l}\text { Drugs } \\
\text { (Number of generic } \\
\text { preparations) }\end{array}$} & \multirow{2}{*}{$\begin{array}{l}\text { Statement } \\
\text { for } \\
\text { women of } \\
\text { childbearing } \\
\text { age* }^{*} \\
\text { Differences } \\
\text { generics } \\
\mathrm{n}(\%)\end{array}$} & \multirow{2}{*}{$\begin{array}{l}\begin{array}{l}\text { Pregnancy } \\
\text { oriented } \\
\text { expression } \\
\text { * }\end{array} \\
\text { Differences } \\
\text { generics } \\
\mathrm{n}(\%)\end{array}$} & \multicolumn{2}{|c|}{$\begin{array}{l}\text { Lactation related } \\
\text { statement }\end{array}$} & \multicolumn{2}{|c|}{$\begin{array}{l}\text { Fertility related } \\
\text { statement }\end{array}$} & \multicolumn{2}{|c|}{$\begin{array}{l}\text { Pregnancy oriented } \\
\text { expression }\end{array}$} & \multicolumn{2}{|c|}{$\begin{array}{l}\text { Lactation related } \\
\text { statement }\end{array}$} \\
\hline & & & $\begin{array}{l}\text { Differences } \\
\text { generics } \\
\mathrm{n}(\%)\end{array}$ & $\begin{array}{l}\text { Major } \\
\text { difference } \\
\mathrm{n}(\%)\end{array}$ & $\begin{array}{l}\text { Differences } \\
\text { generics } \\
\mathrm{n}(\%)\end{array}$ & $\begin{array}{l}\text { Major } \\
\text { difference } \\
n(\%)\end{array}$ & $\begin{array}{l}\text { Differences } \\
\text { generics } \\
\mathrm{n}(\%)\end{array}$ & $\begin{array}{l}\text { Major } \\
\text { difference } \\
\mathrm{n}(\%)\end{array}$ & $\begin{array}{l}\text { Differences } \\
\text { generics } \\
\mathrm{n}(\%)\end{array}$ & $\begin{array}{l}\text { Major } \\
\text { difference } \\
\mathrm{n}(\%)\end{array}$ \\
\hline $\begin{array}{l}\text { Dimenhydrinate } \\
(n=1)\end{array}$ & $0(0.0)$ & $1(100.0)$ & $1(100.0)$ & - & $0(0.0)$ & - & $1(100.0)$ & - & $1(100.0)$ & $1(100.0)$ \\
\hline Ondansetron $(n=31)$ & $11(35.5)$ & $13(41.9)$ & $2(6.5)$ & - & $24(77.4)$ & - & $11(35.5)$ & $11(35.5)$ & $2(6.5)$ & $2(6.5)$ \\
\hline Granisetron $(n=22)$ & $0(0.0)$ & $0(0.0)$ & $3(13.6)$ & $3(13.6)$ & $0(0.0)$ & - & $0(0.0)$ & - & $0(0.0)$ & - \\
\hline Palonosetron $(n=17)$ & $0(0.0)$ & $0(0.0)$ & $0(0.0)$ & - & $2(11.8)$ & $2(11.8)$ & 5 (29.4) & - & $4(23.5)$ & $4(23.5)$ \\
\hline Aprepitant $(n=1)$ & $0(0.0)$ & $100(100.0)$ & $1(100.0)$ & - & $1(100.0)$ & - & $1(100.0)$ & - & $0(0.0)$ & - \\
\hline $\begin{array}{l}\text { Trimethobenzamide } \\
(n=3)\end{array}$ & $3(100.0)$ & $3(100.0)$ & $3(100.0)$ & $3(100.0)$ & $3(100.0)$ & $3(100.0)$ & $3(100.0)$ & - & $3(100.0)$ & $3(100.0)$ \\
\hline Domperidone $(n=4)$ & $0(0.0)$ & $2(50.0)$ & $2(50.0)$ & $2(50.0)$ & $0(0.0)$ & - & $2(50.0)$ & - & $2(50.0)$ & $2(50.0)$ \\
\hline Total $(n=80)$ & 15 (18.8) & $18(22.5)$ & $12(15.0)$ & $8(10.0)$ & $30(37.5)$ & $5(6.3)$ & $23(28.8)$ & $11(13.7)$ & $13(16.3)$ & $12(15.0)$ \\
\hline
\end{tabular}

\section{Table 5. Differences characteristics of the expressions written in the SmPCs/PILs of the drugs with a major difference}

\begin{tabular}{|c|c|c|c|}
\hline \multicolumn{4}{|c|}{ Features of the expressions written in the SmPCs/PILs with major differences } \\
\hline Drug & SmPCs/PILs & $\begin{array}{l}\text { The section of } \\
\text { the statement }\end{array}$ & The reason for the major difference \\
\hline Dimenhydrinate & PIL & Lactation & Lack of drug withdrawal directive $(n=1)$ \\
\hline \multirow{2}{*}{ Ondansetron } & PIL & Pregnancy & Lack of statement stating that the use of the drug is not recommended $(n=11)$ \\
\hline & PIL & Lactation & Lack of the directive not to breastfeed the baby during the use of the drug $(n=2)$ \\
\hline Granisetron & SmPC & Lactation & Lack of the statement that the use of the drug is not recommended $(n=3)$ \\
\hline \multirow{2}{*}{ Palonosetron } & SmPC & Fertility & The difference in the data level regarding the effect of the drug $(n=2)$ \\
\hline & PIL & Lactation & Lack of drug discontinuation directive $(n=4)$ \\
\hline \multirow{3}{*}{ Trimethobenzamide } & SmPC & Lactation & Lack of the statement that the use of the drug is not recommended $(n=3)$ \\
\hline & SmPC & Fertility & The difference in the data level regarding the effect of the drug $(n=3)$ \\
\hline & PIL & Lactation & Lack of directive not to use the drug $(n=3)$ \\
\hline \multirow{2}{*}{ Domperidone } & SmPC & Lactation & $\begin{array}{l}\text { Lack of statement stating the risk of cardiac adverse effects that may occur in the } \\
\text { infant with the use of the drug }(n=1) \\
\text { Presence of a statement that the use of the drug is not recommended }(n=1)\end{array}$ \\
\hline & PIL & Lactation & $\begin{array}{l}\text { Lack of statement stating the risk of cardiac adverse effects that may occur in the } \\
\text { infant with the use of the drug }(n=1) \\
\text { Presence of a statement that the use of the drug is not recommended }(n=1)\end{array}$ \\
\hline
\end{tabular}

milk varies in different preparations of the same active substance also suggests an inconsistency between the preparations. It can be said that these differences are more common in PILs and are also observed prominently when the original and generic preparations are compared. These inconsistencies suggest that the standardization of the expressions regarding pregnancy and lactation period in SmPCs/PILs is not fully ensured and updated information is not reflected in the relevant documents of some 
drugs. On the other hand, although there has been a change in the FDA's risk assessment category for drug use in pregnancy in recent years, in some countries, including Turkey, documents such as SmPCs still use this classification (12). Partial uncertainty and different approaches of the authorities may have contributed to the development of this inconsistency.

It has been reported that $90 \%$ of women are exposed to at least one drug during pregnancy and take an average of 2.6 drugs (13). Between 2000 and 2010, it was reported that more than $97 \%$ of the 172 drugs approved by the FDA had no safety data on teratogenity in humans, and $73 \%$ had no information about their use during pregnancy (5). It is known that 2-3\% of congenital anomalies occur due to drug-related causes, and reducing the risks associated with drug use is among the priorities for protecting public health (14). In our study, the fact that none of the nausea/vomiting drugs known to be used frequently during pregnancy had no indication for use in SmPCs or PILs can be considered as one of the most striking findings. This indicates that the drugs examined are often used out of indication.

In a study examining the SmPCs of 534 preparations in the drug groups frequently used during pregnancy and lactation, registered on the official website of the European Medicines Agency (EMA), it was reported that $89.3 \%$ of the drugs did not contain information on the passage of the drug to the placenta and $61.4 \%$ did not contain information on whether the drug was transferred to breast milk (8). In our study, it was determined that the information regarding whether approximately two-thirds of the drugs passed through the placenta and whether approximately three-fourths of them passed into breast milk was not included in the relevant SmPCs of the drugs. The fact that more space was given to placental passage in SmPCs/PILs examined in our study seems positive for the content of the documents in our country, while the picture is in the opposite direction in passage to milk, reflecting the need to pay more attention to the information on passage to breast milk in the relevant documents. On the other hand, it has been seen that this information is not included in some preparations of metoclopramide, which have been reported to have passed to the placenta, and even not included in any of the preparations of trifluoperazine, ondansetron and granisetron. (15-18). These findings point to problems with standardization and up-to-dateness in terms of information on drug exposure of the fetus in the preparations of some drugs. Unless this information in SmPCs is updated, it can lead to increased incompatibilities with the literature and, as a result, physicians who use these documents when arranging treatment may be misled. As a matter of fact, it has been reported that significant differences in drug use in pregnancy between these documents and drug information systems based on current literature can complicate clinical decisions (19). In order to address the lack of information regarding drug exposure during pregnancy and lactation, postlicensing data must be actively collected, kept up-to-date and included in official sources of information to help make decisions (8).
PILs are one of the important documents that can meet the need for getting information about drug use of pregnant women and nursing mothers. In our study, it was noted that pregnancy was present in $15.3 \%$ of drugs and lactation in $20.3 \%$ under the heading "things to consider before use" in the PILs of the drugs, but the presence of these expressions did not show consistency in all preparations of some drugs. For example, pregnancy was under the relevant heading in about a third of dimenhydrinate and metoclopramide preparations, and about a quarter of ondansetron preparations. Similarly, lactation was under the relevant heading in about a quarter of ondansetron and domperidone preparations and $69 \%$ of metoclopramide preparations. These data suggest that the standard information presented by consensus on a large accumulation of literature on drugs is not sufficiently compatible with the approaches of reflecting this to SmPCs/PILs or specifying this if there is a lack of data. On the other hand, when comparing the documents of the original and generic preparations, there was a greater difference in PILs in both pregnancy and lactation compared to SmPCs. Considering that the target audience of PILs is people with limited health literacy, situations like the information contained in such documents is inconsistent with the treatment planned by the physician or incompatible with the current literature, etc. may cause preparations with the same active substance to give different impressions to the patient. For example, one of the preparations whose documents have been updated at different times may be perceived as more reliable or more risky than the other. It can be considered that this may reduce the patient's compliance with treatment. Whether the variability between PILs containing the same active substance will make a difference in the continuation/discontinuation of the use of the drug by medical illiterate patients should be tested with standardized tests such as readability tests and examined with detailed studies.

It is expected that the information in the SmPCs/PILs of generic drugs will be similar to the originals and consistent in all respects. (20-22). However, similarity or consistency in SmPCs/PILs of drugs may be affected by technical situations such as differences in translations from different languages in the transfer of information of the original preparation to its corresponding documents, or the inability to apply new data/developments simultaneously to the documents of all preparations belonging to the same drug. In our study, when the original and generic preparations of the active substances are compared with each other in terms of expression differences, it can be considered as striking that all but one of the active substances evaluated (aprepitant) have a major difference in their SmPC and/or PIL under at least one heading, and when viewed in detail, a major difference is found in approximately one in every $11 \mathrm{SmPCs}$ and approximately one in every 6 PILs. The fact that major differences are only seen in ondansetron PILs, especially for the statements about pregnancy, seems relatively positive. While there is no major difference in pregnancy-related expressions when comparing original and generic preparations in SmPCs, the fact that there is a major difference in approximately $10 \%$ of lactation-related expressions 
can be associated with the inability to produce generally accepted information due to literature limitations in this field. As a matter of fact, it has been reported that there are no studies on the use of trimethobenzamide, ondansetron, granisetron and palonosetron in lactation, which are the active substances with a major difference in lactation information between the original and generic preparations (23).

According to the current guidelines of the The American College of Obstetricians and Gynecologists (ACOG), metoclopramide is at the advanced stages of the nausea and vomiting treatment algorithm during pregnancy (24). When symptoms persisted following the first pharmacological treatment, it was reported that metoclopramide was one of the drugs that could be considered for auxiliary treatment of nausea and vomiting in pregnant women and did not cause an increase in the risk of teratogenicity $(24,25)$. Widespread use of the drug among pregnant women has been reported up to $86 \%$ (26). In our study, stating that the drug is contraindicated during pregnancy in the SmPCs of two of every five metoclopramide preparations is remarkable in terms of showing that the SmPCs can fall behind the current literature in this regard. On the other hand, the fact that pregnancy is among the contraindications in the SmPCs of nearly half of metoclopramide preparations while the pregnancy category of the drug is " $B$ ", and all of the tropisetron preparations in category " $\mathrm{C}$ " suggests that there are inconsistencies among the mentioned reference sources. In addition, lactation, near half of the metoclodraid preparations, was under the heading "contraindications". Although there have been studies that report that metoclopramidine may cause mild gastrointestinal adverse effects in infants and postpartum depression in mothers, the drug is classified as "compatible with lactation" $(23,27,28)$. Accordingly, it can be said that the preparations that accept the lactation period as contraindications diverge with both other preparations and existing literature information. On the other hand, metoclopramide can be used by some mothers to enhance milk off-label (29). Conflicting results on milk-enhancing effect were reported in studies examining the use of the drug for this purpose $(29,30)$. Moreover, it is reported that the recommended maximum doses and durations can be exceeded in order to achieve this desired effect (31). Therefore, taking into account the risks of abuse, it can be stated that the information about the use of the drug for limited indications such as nausea and vomiting, for the shortest possible time and at the lowest dose, and the information about the risks that may arise if the restrictions are not followed during use should be added to the content of the metoclopramide SmPCs.

In two of the three preparations of dimenhydrinate active substance, lactation was among the contraindications of the drug. Despite the fact that dimenhydrinate can reduce milk production in high doses and prolonged use, and can lead to symptoms such as irritability and drowsiness in infant, it has been reported that low doses and short-term use are not expected to cause such adverse effects and that it is appropriate to use the drug during lactation in the light of long-term clinical experience (32-34). Although the use of the drug for limited doses and durations seems safe in the light of this data, the classification of lactation period as contraindicated in most preparations indicates that these SmPCs/ PILs are incompatible with the updated literature and should be reviewed.

The SmPCs/PILs of two preparations, including the original, of the active substance of domperidone, of which a total of seven preparations were evaluated in the study, contained statements such as "discontinuation of one of the drugs or lactation due to adverse effects that may develop in the baby", and the documents of the other two preparations "the drug is not recommended during the lactation period". Inconsistencies between preparations and inconsistencies with current literature information in other active substances were also in question for domperidone. Domperidone can also be used off-label to increase breast milk during lactation (30). Considering the abundance of the studies related to its use in this field in the literature, the importance of including more standard and compatible expressions about the use of the drug in lactation in the SmPCs/PILs can be better understood (28,35-38).

It is understood that the statement in the original PILs of ondansetron that "the drug is not recommended for use in pregnancy" is not found in more than one-third of the generic PILs. Contrary to the statement in the original PIL, ondansetron is shown among the alternative agents that can be used in resistant nausea and vomiting during pregnancy in the ACOG guideline (24). The use of ondansetron, which has the highest number of preparations among the active substances included in the study, during pregnancy has become widespread in recent years. For example, it was reported in the USA in 2014 that women who were prescribed ondansetron during pregnancy accounted for about a quarter of all pregnant women (39). However, despite its frequent use, important results that may contradict each other have been reported from recent studies on fetal safety data of the drug. (40-42). Accordingly, in 2019, EMA stated that the drug should not be used in the period in question due to the conflicting results regarding the cardiac malformations that may develop in the fetus due to ondansetron and the possible increased risk of orofacial malformation in the first trimester (43). However, the EMA's sharp approach was not accepted by the European Network of Teratology Information Services (ENTIS) (44). Unlike the EMA, the British Medicines and Healthcare products Regulatory Agency recommended that the benefit/risk calculation be made before the use of ondansetron by women in the first trimester of pregnancy (45). The contradictory results reported in the literature may have paved the way for the incompatibility between the preparations of ondansetron compared to the other drugs with original-generic preparation differences in our study. Moreover, the fact that there is still no consensus among international health authorities on the fetal safety status of the drug may make it difficult to include clear recommendations on the use of the drug in SmPCs/PILs. However, it is clear that attempts to standardize these documents are needed to ensure more rational use of the drug by physicians and patients. 


\section{REFERENCES}

\section{Study Limitations}

In ourstudy, the current marketavailability of the preparations whose SmPCs/PILs were examined were not taken into consideration, and the most up-to-date documents in TMMDA were evaluated within the data collection process of these products within the scope of the research. SmPCs/PILs information on preparations that are not available in the market may contain some differences compared to preparations available in the market. The fact that this situation could not be evaluated in detail within the scope of the study can be accepted as a limitation. However, the fact that all preparations registered in TMMDA have been examined, has enabled a broader data to be presented regarding the differences detected in SmPCs/PILs. Other limitations of the study are that the differences between the generic preparations of the same drug were not elaborated and the combined preparations were not examined. In addition, since it is not known whether the differences determined in PILs make a difference in the patient's perception of the use of the drug, the relevant inferences should be interpreted in this context and verified with studies including reading tests.

\section{Conclusion}

It is noteworthy that none of the nausea and vomiting drugs used in special populations such as pregnant women and lactation mothers have indications of these periods in their SmPCs or PILs. The fact that different expressions are encountered in the information that should be included in these documents may be associated with the absence of these indications. Although the differences between the original and generic preparations of drugs are mostly evaluated as minor, the detection of a major difference in at least one of the titles examined in the SmPCs or PILs of all preparations except aprepitant points out the necessity of standardization by reflecting the changes in the current literature to these documents at frequent intervals. However, the differences determined in PILs may cause confusion in terms of interlocutors, especially patients. The impression of this situation on the patients needs to be evaluated with more comprehensive reading tests. It is thought that the determinations made in this study will contribute to the elimination of obstacles on the way that SmPCs/PILs contain up-to-date information, are more guiding and user friendly, from the perspective of pregnancy and lactation.

Ethics Committee Approval: The study does not require ethics committee approval.

Informed Consent: This study did not require patient consent because it did not contain any patient data.

Peer-review: Externally peer-reviewed.

Author Contributions: Concept - A.A., V.A., D.B., A.B.; Design - V.A., A.B., D.B., A.A., C.V.; Data Collection and/or Processing - A.B., V.A, D.B.; Analysis and/or Interpretation - V.A., D.B., A.B., C.V., A.A.; Literature Search - C.V., D.B., A.B., V.A.; Writing - V.A., A.B., D.B., C.V., A.A.

Conflict of Interest: The authors have no conflict of interest to declare.

Financial Disclosure: The authors declared that this study has received no financial support.
1. Broussard CS, Frey MT, Hernandez-Diaz S, Greene MF, Chambers CD, Sahin L, et al. Developing a systematic approach to safer medication use during pregnancy: summary of a centers for disease control and prevention-convened meeting. Am J Obstet Gynecol 2014; 211: 20814.

2. Ansari J, Carvalho B, Shafer SL, Flood P. Pharmacokinetics and pharmocodynamics of drugs commonly used in pregnancy and parturition. Anesth Analg 2016; 122: 786-804.

3. Vargesson N. Thalidomide-induced teratogenesis: history and mechanisms. Birth Defects Res C Embryo Today 2015; 105 :140-56.

4. Sheffield JS, Siegel D, Mirochnick M, Heine RP, Nguyen C, Bergman KL, et al. Designing drug trials: considerations for pregnant women. Clin Infect Dis 2014; 59: 437-44.

5. Adam MP, Polifka JE, Friedman JM. Evolving knowledge of the teratogenicity of medications in human pregnancy. Am J Med Genet Part C Semin Med Genet 2011; 157: 175-82.

6. T.C. Sağlık Bakanlığı. Beşeri Tıbbi Ürünler Ruhsatlandırma Yönetmeliği. Resmî Gazete. Tarih No: 19.01.2005; Sayı: 25705. Son Erişim Tarihi: Erişim Adresi: https://www.resmigazete.gov.tr/eskiler/2005/01/20050119-7.htm (accessed May 2020).

7. Bayram D, Aydın $\mathrm{V}, \mathrm{Akı \textrm {C }} A$. Investigation of warnings regarding driving and machine use in summary of product characteristics and patient information leaflets of drugs frequently used in Psychiatry. Gazi Med J 2020; 31: 38-43.

8. Arguello B, Salgado TM, Fernandez-Llimos F. Assessing the information in the summaries of product characteristics for the use of medicines in pregnancy and lactation. Br J Clin Pharmacol 2015; 79: 537-44.

9. Einarson TR, Piwko C, Koren G. Quantifying the global rates of nausea and vomiting of pregnancy: a meta analysis. J Popul Ther Clin Pharmacol 2013; 20: e171-83. Epub 2013 Jul 13.

10. Mazzotta P, Magee LA. A risk-benefit assessment of pharmacological and nonpharmacological treatments for nausea and vomiting of pregnancy. Drugs 2000; 59: 781-800.

11. Lynch MM, Amoozegar JB, McClure EM, Squiers LB, Broussard CS, Lind JN, et al. Improving safe use of medications during pregnancy: the roles of patients, physicians, and pharmacists. Qual Health Res 2017; 27: 2071 80.

12. Food and Drug Administration, Department of Health and Human Services. Content and Format of Labeling for Human Prescription Drug and Biological Products; Requirements for Pregnancy and Lactation Labeling. Federal Register 2014; 79 :72064-103. Available from: https:// www.federalregister.gov/documents/2014/12/04/2014-28241/contentand-format-of-labeling-for-human-prescription-drug-and-biologicalproducts-requirements-for

13. Mitchell AA, Gilboa SM, Werler MM, Kelley KE, Louik C, Hernández-Díaz S. Medication use during pregnancy, with particular focus on prescription drugs: 1976-2008. Am J Obstet Gynecol 2011; 205: 51.

14. Burkey BW, Holmes AP. Evaluating medication use in pregnancy and lactation: what every pharmacist should know. J Pediatr Pharmacol Ther 2013; 18: 247-58.

15. Arvela P, Jouppila R, Kauppila A, Pakarinen A, Pelkonen O, Tuimala R. Placental transfer and hormonal effects of metoclopramide. Eur $\mathrm{J}$ Clin Pharmacol 1983; 24: 345-8.

16. Siu SS, Chan MT, Lau TK. Placental transfer of ondansetron during early human pregnancy. Clin Pharmacokinet 2006; 45: 419-23.

17. Weiner CP. Drugs for pregnant and lactating women. E-Book. 3rd ed. Elsevier Health Sciences, 2018.

18. Julius JM, Tindall A, Moise KJ, Refuerzo JS, Berens PD, Smith JA. Evaluation of the maternal-fetal transfer of granisetron in an ex vivo placenta perfusion model. Reprod Toxicol 2014; 49: 43-7.

19. Frost Widnes SK, Schjøtt J. Advice on drug safety in pregnancy: are there differences between commonly used sources of information? Drug Saf 2008; 31: 799-806.

20. European Medicines Agency. ORD general principles regarding the SmPC information for a generic/ hybrid/ biosimilar product. EMA/627621/2011;2018 Available from: https://www.ema.europa.eu/en/ documents/regulatory-procedural-guideline/quality-review-documentsgeneral-principles-regarding-summary-product-characteristicsinformation/hybrid/biosimilar-product_en.pdf (accessed May 2020) 
21. T.C. Sağlık Bakanlığı. Beşeri Tıbbi Ürünler Ruhsatlandırma Yönetmeliği. Resmî Gazete. 19.01.2005; Sayl: 25705 Erişim Adresi: https://www. resmigazete.gov.tr/eskiler/2005/01/20050119-7.htm (accessed May 2020)

22. Sağlık Bakanlığı, Ilaç ve Eczacılık Genel Müdürlüğü. Kısa Ürün Bilgisi Standart Değerlendirme Prosedürü. 26.02.2008. Erişim Adresi: https:// docplayer.biz.tr/6598279-Kisa-urun-bilgisi-standart-degerlendirmeproseduru-26-02-2008-ilac-ve-eczacilik-genel-mudurlugu.html

23. Briggs GG, Freeman RK, Tower CV, Forinash AB. Drugs in pregnancy and lactation: a reference guide to fetal and neonatal risk. 11th ed. Philadelphia, PA: Wolters Kluwer; 2017.

24. Erick M, Cox JT, Mogensen KM. ACOG practice bulletin 189: nausea and vomiting of pregnancy. Obstet Gynecol 2018; 131: 935.

25. Pasternak B, Svanström H, Mølgaard-Nielsen D, Melbye M, Hviid A. Metoclopramide in pregnancy and risk of major congenital malformations and fetal death. JAMA 2013; 310: 1601-11.

26. Raymond $\mathrm{SH}$. A survey of prescribing for the management of nausea and vomiting in pregnancy in Australasia. Aust N Z J Obstet Gynaecol 2013; 53: 358-62.

27. Zuppa AA, Sindico P, Orchi C, Carducci C, Cardiello V, Romagnoli C. Safety and efficacy of galactogogues: substances that induce, maintain and increase breast milk production. J Pharm Pharm Sci 2010; 13: 162-74.

28. Ingram J, Taylor H, Churchill C, Pike A, Greenwood R. Metoclopramide or domperidone for increasing maternal breast milk output: a randomised controlled trial. Arch Dis Child Fetal Neonatal Ed 2012; 97: F241-5. doi: 10.1136/archdischild-2011-300601.

29. Asztalos EV. Supporting mothers of very preterm infants and breast milk production: a review of the role of galactogogues. Nutrients. 2018; 10: 600.

30. Brodribb W, Academy of Breastfeeding Medicine. ABM Clinical Protocol \#9: use of galactogogues in initiating or augmenting maternal milk production, second revision 2018. Breastfeed Med 2018; 13: 307-14.

31. Svendsen K, Wood M, Olsson E, Nordeng H. Reported time to onset of neurological adverse drug reactions among different age and gender groups using metoclopramide: an analysis of the global database Vigibase®. Eur J Clin Pharmacol 2018; 74: 627-36.

32. Ito S, Blajchman A, Stephenson M, Eliopoulos C, Koren G. Prospective follow-up of adverse reactions in breast-fed infants exposed to maternal medication. Am J Obstet Gynecol 1993; 168: 1393-9.

33. Drugs and Lactation Database. Dimenhydrinate. US National Library of Medicine website. Available from: https://www.ncbi.nlm.nih.gov/books/ NBK501867/ (accessed May 2020)
34. Buhimschi CS, Weiner CP. Medications in pregnancy and lactation: Part 2. Drugs with minimal or unknown human teratogenic effect. Obstet Gynecol 2009; 113: 417-32.

35. Osadchy A, Moretti ME, Koren G. Effect of domperidone on insufficient lactation in puerperal women: a systematic review and meta-analysis of randomized controlled trials. Obstet Gynecol Int 2012; 2012: 642893. doi: 10.1155/2012/642893

36. Anderson PO. Domperidone: the forbidden fruit. Breastfeed Med 2017; 12: $258-60$.

37. Asztalos EV, Campbell-Yeo M, da Silva OP, Ito S, Kiss A, Knoppert D. Collaborative Group. Enhancing human milk production with domperidone in mothers of preterm infants. J Hum Lact 2017; 33: 181-7.

38. da Silva OP, Knoppert DC, Angelini MM, Forret PA. Effect of domperidone on milk production in mothers of premature newborns: a randomized, double-blind, placebo-controlled trial. CMAJ 2001; 164: 17-21.

39. Taylor LG, Bird ST, Sahin L, Tassinari MS, Greene P, Reichman ME, et al. Antiemetic use among pregnant women in the United States: the escalating use of ondansetron. Pharmacoepidemiol Drug Saf 2017; 26: 592-6.

40. Kaplan YC, Richardson JL, Keskin-Arslan E, Erol-Coskun H, Kennedy D. Use of ondansetron during pregnancy and the risk of major congenital malformations: a systematic review and meta-analysis. Reprod Toxicol 2019; 86: 1-13.

41. Zambelli-Weiner A, Via C, Yuen M, Weiner DJ, Kirby RS. First trimester ondansetron exposure and risk of structural birth defects. Reprod Toxicol 2019; 83: 14-20.

42. Huybrechts KF, Hernández-Díaz S, Straub L, Gray KJ, Zhu Y, Patorno E, et al. Association of maternal first-trimester ondansetron use with cardiac malformations and oral clefts in offspring. JAMA 2018; 320: 2429-37.

43. European Medicines Agency. PRAC recommendations on signals. EMA/ PRAC/347675/2019; 2019 Available from: https://www.ema.europa.eu/ en/documents/prac-recommendation/prac-recommendations-signalsadopted-8-11-july-2019-prac-meeting_en.pdf (accessed May 2020)

44. European Network of Teratology Information Services. ENTIS official response to the EMA recommendations concerning ondansetron use by pregnant women. 2019. Available from: https://www.entis-org.eu/ wp-content/uploads/2019/09/Ondansetron-PRAC-ENTIS-ResponseStatement-FINAL.pdf (accessed May 2020)

45. Drug Safety Update volume 13, issue 6: January 2020: 2. Available from: https://assets.publishing.service.gov.uk/government/uploads/system/ uploads/attachment_data/file/861112/Jan-2020-PDF-final.pdf (accessed May 2020) 